\title{
APROXIMACIÓN A LA EPISTEMOLOCÍA DE LA EDUCACIÓN ARTÍSTICA
}

Por

Jaime Ruìz Solórzano*

\section{RESUMEN}

Este escrito es un primer abordaje, a la epistemología de la educación artistica, entendida como epistemología regional, o sea, que da cuenta de un saber específico; para ello se han articulado tres partes: la primera trata sobre los conceptos fundamentales como educación, arte, educación artística, en la segunda se establece un recuento sobre el aprendizaje y la enseñanza de la educación artistica teniendo en cuenta las experiencias más significativas de la formación y la educación artística desde el arte de las cavernas y precolombino hasta nuestros días; la tercera sintetiza las teorías contemporáneas más relevantes de la educación artística.

\section{PALABRAS CLAVES}

Educación, arte, educación artística, teorias contemporáneas de la educación artística.

*Pintor egresado de la Escuela de Artes de Bogotá, Licenciado en filosofía e historia de la Universidad Santo Tomás, especialista en planeación del Desarrollo Educativo y Cultural; cursó estudios de maestria en Educación por el Arte y animación sociocultural en el Instituto Pedagógico Latinoamericano y Caribeño IPIAC de la Habana, Cuba. Actualmente es Jefe de Programa de Artes Visuales y docente del Departamento de Artes. 


\section{ANALISIS CONCEPTUAL DE LA EDUCACIÓN ARTÍSTICA}

\subsection{La definición del área de conocimiento}

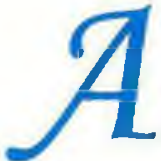

ntes de avanzar en el análisis lingüistico

es preciso anticipar que éste es un texto no exento de dificultades, dado que en nuestro medio no existe literatura disponible sobre la definición de la «epistemologia de la Educación Artístican, cuyo término constituye una expresión polisémica.

La utilización de conceptos polisémicos es concomitante a distintas concepciones e interpretaciones sobre un tópico de análisis dado. Por ello es indispensable hacer mención siempre a la época, lugar y contexto de referencia sociocultural para entender, comprender o como minimo acercarnos al sentido que se le pretende dar a la Educación Artística. ¿Qué entendemos o qué se ha entendido hasta hoy en nuestro país por Educación Artistica? ¿Qué tipos de educación ha desarrollado esta educación artística a través del tiempo? ¿Cuáles son las principales corrientes y tendencias teóricas contemporáneas de la Educación Artística?. En otros términos, ¿cuál es la situación teórica que orienta el aprendizaje enseñanza de la educación artística? Una aproximación a la epistemología de la educación artistica, en consecuencia, requiere la definición de los conceptos claves, la revisión de su devenir, y el análisis de las teorias que soportan a la Educación Artística, como punto de partida de una epistemologia regional por construir, que con el tiempo y la reflexión interdisciplinaria probablemente alcanzará una mayor definición y especificidad.

La expresión «Educación Artistica», en sentido gramatical, es un concepto que se ha construido sobre la base del sustantivo "educación» y al calificativo "artistica», lo cual establece el carácter de la educación en mención. Esta adjetivación especifica y determina que la naturaleza de la misma posee carácter artístico. Pero bien, ¿Qué significa cada concepto?, veamos.

\subsection{El Concepto de Educación}

De acuerdo con los diccionarios el análisis etimológico del término «educación" se origina en la lengua latina con doble sentido y significado. Inicialmente, procede del verbo latino "educare" que significa guiar, orientar, conducir; un segundo sentido corresponde a la expresión «educere» significando extraer, dar a luz, hacer salir.

En consecuencia, desde las primeras teorias pedagógicas, estos dos significados han permitido la simultaneidad de dos modelos conceptuales básicos. El modelo de la "escuela tradicional" de carácter directivo y el modelo de la «escuela nueva o moderna" que postula como axioma pedagógico la activa participación del estudiante, tanto en las actividades fisicas como intelectuales.

En oposición a la filosofía de la educación tradicional, que avala la autoridad del maestro y la hegemonia tanto o de los métodos como de los contenidos, en perjuicio de los alumnos, se anteponen las ideas naturalistas y libertarias de J. J. Rousseau (1712-1778), las filantrópicas de J. Basedow (1723-1790) y desde el campo de la psicologia evolutiva los aportes de J. Piaget, enfoque que determinó el principio pedagógico que todo proceso educativo debe tener al niño o estudiante como centro, teniendo en cuenta sus intereses, necesidades y desarrollo biosicosocial.

En la actualidad los filósofos y teóricos de la educación no provilegian el predominio de un modelo sobre el otro, la mayoría de ellos apuestan al principio la relatividad de estos modelos, ya que en el proceso educativo y formativo se opta por aprendizajes donde se conjugan. Esta posición ecléctica concuerda con 
un tercer modelo o teoría pedagógica, estructurada como sintesis de ambas, conocida como personalismo pedagógico.

La caracteristica fundamental del personalismo pedagógico radica en la libertad humana, aunque es también relativa al encontrarse contextualizada o condicionada por la naturaleza, la cultura y la historia particular de cada colectivo social. En esencia, la clave explicativa de la anterior afirmación se puede encontrar en los conceptos de "educabilidad", "enseñabilidad" $\mathrm{y}$ «contexto» con sus respectivas implicaciones.

La educabilidad es la condición intrinseca de cada persona para conocer, es la capacidad de autodeterminación que impele a los sujetos a desarrollarse como personas y a la adquisición de aprendizajes, sobre todo cuando son significativos, es también la capacidad que tiene cada persona para asimilar y acomodarse al entorno; en si, es la posibilidad que tienen las personas por el hecho de ser seres biopsicosociales de introyectar todos aquellos procesos que le convierten en creador, artista y productor inteligente, con lo que no sólo se inserta en el medio circundante sino que le proyecta para transformarlo y convertirse en un generador de cultura, entendida ésta, en sentido amplio y con enfoque antropológico holístico.

Por su parte la enseñabilidad obedece al interrogante sobre el qué enseñar, lo cual exige la comunicabilidad de los distintos saberes, posibilitando el desarrollo de las estructuras del pensamiento y la identificación de la metacognición en los estudiantes para producir nuevos conocimientos.

De otro lado, la identificación del contexto se hace evidente en la creación de ambientes y climas de aprendizaje adecuados y pertinentes, que permiten actuar con suficiencia para responder a las realidades especificas, a una cultura con necesidades concretas, porque es precisamente la educación el sector que permite dinamizar la cultura, siempre y cuando sea orientada desde un proyecto curricular emancipador.

Desde la anterior perspectiva la educación no puede basarse en ninguna hegemonía, ni la que tiene el educador y el método como ejes de desarrollo o "logo-magistrocentrismo didáctico", como se creía en la educación tradicional; como tampoco en las únicas, inquietudes e intereses de los alumnos «paido-centrismo pedagógico». Por lo tanto, la educación es un construir permanente, donde las posiciones eclécticas deben predominar, por encima de cualquier polarización, permitiendo desarrollar las distintas potencialidades e inteligencias de todas las personas.

Pero, ¿qué se entiende por Arte? Especialmente ¿qué se entiende por arte como componente significativo de la Educación Artistica?

\subsection{El Concepto de Arte}

Se suele decir que «el arte constituye, en todas sus formas de expresión, uno de los tópicos educativos más complejos", por cinco razones: 1) El arte en sus diversas formas, se encuentra presente en todas las culturas y civilizaciónes. 2) Quienes se ocupan de la práctica o la teoria del arte por lo general eluden la definición del mismo. 3) Con frecuencia la práctica artística es un trabajo asumido en la soledad individual, por lo menos a nivel conceptual. 4) La habilidad para su aprendizaje se relaciona con las aptitudes e intereses personales. 5) Como consecuencia de las razones anteriores, las enseñanzas artísticas habitualmente se consideran dificiles de enseñar. (1).

Otros aspectos hacen difícil la definición del arte: primero, desde la sociedad no se puede hablar de arte sin connotar productos con 


\section{Aproximación a la epistemologia de la educación artística.}

significación cultural; segundo consideramos arte a una forma de expresión de la moderna civilización euro americana; tercero, a los niños se les inculca en la escuela la idea de que arte es una categoría de actividades y productos especializados; con lo cual aprenden que lo que ellos realizan son actividades artísticas (2); cuarto, se produce confusión en casi toda la sociedad, sobre todo en la que no tenido posibilidad de acceder a la educación artística, al denominar arte el llamado "arte de masas» debido a su reproducción mecánica, al montaje de grandes espectáculos o las prácticas que requieren cierto dominio del sentido estético como la floristería, la peluquería, la moda, etc. (3).

Sin embargo, el arte tiene distintas connotaciones dependiendo desde el ámbito disciplinar que se le defina:

Semánticamente: proviene del término griego Poyetés Technè y su traducción romana literal Arts Poética en cuanto a su significación comprendida como «una suma o conjunto de conocimientos o una forma de adiestramiento especializado...en su desarrollo la palabra latina Arts vino a ganar la carrera a la palabra Poyetés y tanto en lenguas románicas como en las sajonas, terminó englobando todo el conjunto de quehaceres que hoy denominamos artísticos, mientras que la palabra griega redujo su campo de acción para definir una actividad más especificamente circunscrita, la de una faena literaria, la poesia». (4).

Subjetivamente: Señala los procedimientos, empleo de técnicas y materiales con los que crean o producen las obras artistica bidimensionales, tridimensionales, icónicas o puestas en escena en el espacio y tiempo especificos.

Materialmente: Alude al resultado formal de esa producción, al objeto material en sí, es decir la transformación del material y los respectivos soportes recurriendo a una técnica o un proceso.
Psicológicamente: Tiene varios intereses alrededor del despliegue de la creatividad y los fenómenos internos suscitados en el proceso interno del creador. Además estudia la percepción y los efectos que produce la experiencia estética o artística sobre los espectadores o consumidores.

Antropológicamente: Son todas las expresiones o manifestaciones productivas de una cultura o civilización.

Sociológicamente: la obra de arte puede entenderse como un valor existencial, individual o colectivo, como una forma de objetivación del ser humano.

Popularmente: toma la acepción de todo saber no metódico, poco riguroso, perteneciente a los grupos subalternos opuesto al arte de los grupos hegemónicos y que para ejercitarlo se necesitan más cualidades o talento que capacidad intelectual. En esencia, existe la tendencia a considerar con amplitud lo que se entiende por Arte, oscilando entre concepciones generales y otras más específicas nexadas con el desempeño de habilidades o la elaboración de productos más que con una forma especifica de actividad y consecuente campo de conocimiento. Es decir que en el fondo subyace una serie de concepciones utilitaristas, hoy conceptualizadas como actividades efimeras. (5).

Estéticamente: Se refiere al término griego Aistesis, con lo cual se alude a la sensibilidad y su imbricación con las principales categorias estéticas: Belleza-Fealdad, Lo trágico-Lo cómico, Lo sublime-Lo grotesco, además de Lo Estético término probablemente mucho más discutido que alude a "la cualidad de un objeto humano, o humanizado, peculiar, no importa si es natural o artificial, al que por su forma sensible le es inmanente cierto significado". (6). 
Políticamente: Se relaciona con la inmensa capacidad de especulación y su uso como propaganda que permite a los partidos señalar el «valor político»y la efectividad del producto para conmover, movilizar o "denunciar" grupos sociales.

Económicamente: Se basa en el valor del producto comercial del arte, inscrito dentro de un sistema de producción-difusión-valoraciónconsumo y sujeto a las leyes del mercado, de manera similar a como circula cualquier artículo fabricado dentro de las sociedades capitalistas. (7).

En consecuencia, si la educación y el arte solamente se perciben en los términos impuestos por la sociedad de consumo y

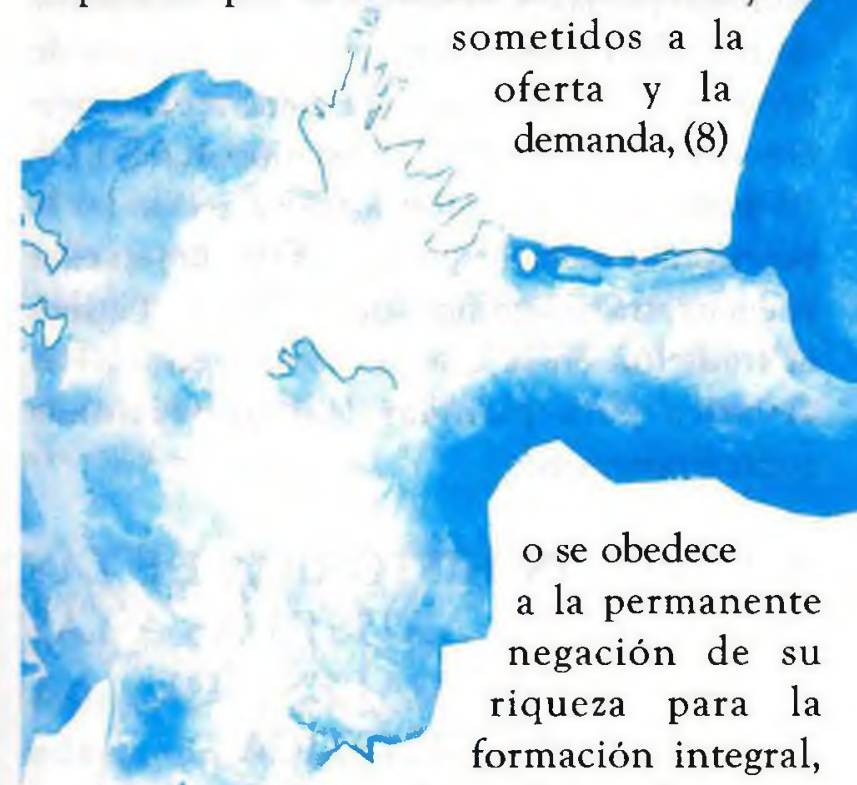

sobre todo en culturas tan defectivas como las nuestras, la educación artística no pasará del umbral de lo agregado o superfluo, como tradicionalmente se le ha concebido.

Gadamer nos da tres razones para explicar esta situación: 1) el inmenso progreso obtenido por la CIENCIA MODERNA NATURAL. 2) como consecuencia de este progreso la RACIONALIZACIÓN creciente de la sociedad. 3) como consecuencia de las dos anteriores el rumbo TÉCNICO y
CIENTÍFICO dado a la dirección social de nuestra época. (9).

\subsection{El Concepto de Educación Artística}

Dentro de quienes se encargan de orientar la categoria de Educación Artística comúnmente circulan expresiones como educación estética, formación artística, educación por el arte, expresión plástica, expresión musical, expresión corporal, artes dramáticas, teatro, danzas artes escénicas, bellas artes, artes plásticas, artes visuales, dibujo, pintura, cerámica, grabado y música, para hacer referencia a las disciplinas a través de las cuales se expresa el arte. Pero también en las prácticas educativas se unen ámbitos afines como el dibujo técnico, el diseño gráfico la fotografía, la geometría descriptiva, las artes manuales, la pantomima, elaboración de instrumentos etc., por lo general siempre sentado en el hacer por el hacer y sin clara conciencia de lo que se requiere, ni una teoría o conceptualización que oriente la Educación Artistica.

Acha ha explicado la dinámica que se genera entre la tradición y la innovación para avanzar de manera creativa; es decir, que se depende de las conquistas anteriores para realizar nuevas propuestas. Sin embargo, cada una de ellas parece constituirse en un poderoso condicionante de los nuevos desarrollos, si el propósito de quien orienta los procesos no se preocupa por vivir actualizado y con una actitud positiva hacia las tendencias vigentes y atento a las emergentes innovadoras, con lo último solamente es factible la generación de propuestas que vayan a la par o muy cercanas a los tiempos actuales (10).

Es por ello que debemos poner en perspectiva que el aprendizaje y la enseñanza del arte son factibles de abordar en cuatro modalidades distintas: la educación artística, la formación artística, la educación por el arte y la educación 
estética, que aunque tienen nexos sólidos son bien particulares. La educación artística, se diferencia como actividad pedagógica de integración a la escolarización sin fines de especialidad artística; la formación artística, corresponde a la actividad pedagógica dirigida a la profesionalización de la producción artística; y la educación por el arte como actividad pedagógica, busca facilitar los procesos de aprendizaje enseñanza, de cualquier saber a través de los lenguajes artisticos. (11).

En las teorias que orientan los programas de educación artística son aceptados los planteamientos elaborados por Herbert Read para la educación estética donde se identifican todos los movimientos culturales y los profesionales de educación artística, formación artística y educación por el arte que conciben a la persona como ser integral, creativa y libre. A partir de la integración de los distintos lenguajes artísticos Read explica en sintesis que la educación se guiará por la obtención de los siguientes propósitos:

- La conservación de la intensidad natural de todos los modos de percepción y sensación.

- La coordinación de los diversos modos de percepción y sensación entre sí y en la relación con el ambiente.

- La expresión del sentimiento en forma comunicable.

- La expresión de forma comunicable de los modos de experiencia mental que, sino no fuera asi, permanecerian parcial o totalmente inconscientes. (12).

De otra parte, el concepto de educación en su significado sociológico se asume como un perfeccionamiento de la persona, el cual se produce en los seres inteligentes con la coordinación de sus movimientos a la vez que desarrolla su mente, todo ello contribuye a la adquisición de conocimientos como una reafirmación de si mismo en relación con la naturaleza. La persona adquiere y produce este conocimiento interactuando con su entorno natural y artificial, en el ejercicio de su estructura biológica y psicológica con el medio ambiente natural. La educación se concluye como una constante reorganización de las experiencias humanas. (13).

La concepción de la educación como reconstrucción y construcción continúa de la experiencia es compatible con la educación artística, donde se identifica el resultado y el proceso. Implica la reconstrucción de la experiencia articulada como un proceso activo, asumido por las personas participantes, a partir de una clara planificación, determinación de propósitos y diseño de procesos de aprendizajeenseñanza en contextos claramente situados. De tal manera la educación artística reside en la posesión de dichas experiencias porque en ellas se encuentra su significación. (14) Pero, ¿Cuál es la tradición en la que se basa la educación artistica para plantear las innovaciones contemporáneas?

\section{REVISIÓN HISTÓRICA DE LAS ACTIVIDADES ARTÍSTICAS A LAS TEORÍA ACTUALES DE LA EDUCACIÓN ARTIISTICA}

De hecho las prácticas y eventos artísticos inician con el desarrollo de la humanidad como una necesidad consubstancial a su devenir en el mundo. Para ello se han dado múltiples explicaciones sobre su manifestación alrededor del año 35.000 a. C. en el área franco cantábrica europea, aproximadamente en el 12.000 a. C. en la zona de Iztapalapa en México, donde se encontraron los restos más antiguos del hombre de Latinoamérica, y hacia el 11.000 a. C., correspondiente a la etapa lítica o paleoindia, con varios hallazgos en nuestro pais. 
Se discutia si se podia llamar arte a las necedades primigenias de conjurar las fuerzas de la naturaleza, a los desarrollos tecnológicos incipientes, a los juegos y pasatiempos dentro de un mundo mágico mítico. Pero hoy existe conciencia y se acepta que el hombre desde el principio tuvo necesidad de transformar el medio y los materiales como una forma de adaptación, pero también como una manera de embellecer su entorno con un sentido estético.

Igualmente el arte y su lenguaje son comunes a todas las culturas y a las grandes civilizaciones de Egipto, China, India, Mesopotamia, que datan del 4.000 a. C., y a «nuestros griegos», como los denominara Alcina Franch; es decir, a las culturas teocráticas preztecas y preincas entre el 300 a. C. y el 900 d. C.; a las connotadas civilizaciones Azteca, Maya e Inca del 1.000 a 1.500 ; y a nuestras culturas precolombinas colombianas del 300 a. C. al siglo XVI. No se tiene conocimiento cómo se realizaba el aprendizaje y la enseñanza del arte, pero es casi seguro que era una práctica aprendida por observación y repetición, cuando no siguiendo reglas y dictados de quienes encargaban las obras.

Dentro de la Civilización Clásica, sustrato fundamental de la cultura occidental y a cuya órbita también pertenecemos, se tiene referencia de la importancia del arte y de la educación artistica para sus respectivas sociedades. Si bien el arte ocupaba un lugar destacado, se consideraba indigno y de ocupación inferior para educar la progenie de las élites. Se tiene poca «información sobre los métodos empleados para formar a los futuros músicos, escultores, arquitectos, artesanos... Aprendian sus oficios en los talleres familiares donde el padre trasmitia sus habilidades a los hijos. En ocasiones, se introducian personas ajenas a la familia como aprendices. En la última época del Imperio Romano, el emperador promovía el estudio de la arquitectura con la concesión de un estipendio a los estudiantes de mayor talento, gracias a lo cual la carrera adquirió un estatus más elevado». (15).

Es conocido el modelo educativo ateniense caracterizado por su equilibrio entre el cultivo del cuerpo del intelecto, es decir se inculcaba la práctica de la gimnasia y de la música. Considerando que el último término en su sentido original aludia «a cualquiera de las artes y de las ciencias que se hallaban bajo el dominio de las musas». Era común el «texto cantado y el acompañamiento instrumental, que se consideraba un elemento necesario dentro de las habilidades de todo hombre nacido libre". En este contexto "Las primeras clases de dibujo tuvieron lugar en Sición, en el siglo IV a. C. ... Y de alli se extendió al conjunto de Grecia. Aristóteles las clasificó como una asignatura extra que los alumnos añadian a su currículo normal de literatura, gimnasia y música... Durante el siglo II a. C. aparecía clasificado como una de las asignaturas de los exámenes de las escuelas de Teos y Magnesia del Meandro... El principal objetivo de la enseñanza del dibujo era convertir a los estudiantes en jueces de la belleza de la forma humana». (16).

Roma como heredera directa de la cultura griega asimiló y naturalizó sus más valiosas enseñanzas filosóficas, retóricas y artísticas. Al respecto los romanos de la aristocracia también adquirieron el hábito de realizar colecciones de arte, sobre todo de estatuas o de copias griegas. Hacia el final de la hegemonía romana se habla de emperadores que "aprendieron a dibujar y a pintar» o inculcaron el desarrollo de estas habilidades a sus hijos. En el siglo III d. C. Plotino desarrolló una filosofía basada en la belleza teniendo como referente las enseñanzas de Platón. "Según Plotino, el artista inspirado es capaz de encarnar las formas platónicas en los materiales de este mundo gracias a un poder que le confieren las actividades de su alma. Dicho artista no se limita a representar objetos naturales tal como se presentaban a sus ojos, sino que también es capaz de añadir aquello que falta en la naturaleza... El arte no es mera 
imitación, a diferencia de lo que pensaba Platón, también es una revelación... Constituia una forma de aprehensión intelectual, pues hace que las formas sean accesibles a los sentidoș». (17).

La Edad Media es el período de la historia europea que transcurrió desde la desintegración del Imperio romano de Occidente hasta el Renacimiento, lo cual comprende del siglo V, hasta el siglo XV. El término significó en su origen una parálisis del progreso, de estancamiento cultural, predominio de la ideología religiosa y el sistema feudal basado en la tenencia de la tierra.

Con la caida del Imperio Romano los conventos y los monjes conservaron algunos elementos culturales sobrevivieron al mundo clásico. En la Alta Edad Media, el conocimiento de la ciencia empezó a ser considerado fundamental a través de las siete artes liberales del currículo medieval, organizado en dos grados, el elemental trivium que estaba configurado por la gramática, la retórica y la lógica o dialéctica; y el más avanzado quadrivium por la aritmética, la astronomia, la geometria y la música.

Para ejemplarizar la educación artística de la edad media podemos tomar el ejemplo de la organización que se sucedia en la elaboración de los manuscritos miniados o libros dibujados a mano. Estos libros eran enriquecidos por los artistas con decoraciones y pinturas. Las iluminaciones se llaman también miniaturas; el término procede del latín minium (minio), pigmento que se utilizaba antiguamente para marcar las letras iniciales del texto; no hace alusión los formatos de reducido tamaño de cada pintura.
La elaboración de los manuscritos implicaba la participación de distintos responsables, en orden sucesivo el escriba diseñaba las letras, el pintor aplicaba y brillaba la capa dorada y el encuadernador armaba el libro. En el trabajo de cada libro los creadores aportaban de acuerdo con su saber y experiencia, encabezando la labor el maestro secundado por sus asistentes. De esta manera los monjes del scriptorium adquirian sus destrezas en el desarrollo del mismo trabajo, bajo la guia y supervisión de quien fuese su maestro o del superior eclesiástico.

Durante la Baja Edad Media la sociedad europea se urbaniza. Alrededor de la mancha poblacional de los burgos, que van creciendo adyacentes a las fortalezas de los señores, se generan micro sociedades con divisiones de trabajo cada vez más diferenciadas y especializadas. De otra parte, el resurgimiento de los mercados en sitios estratégicos, motiva la organización de la construcción y la producción de los objetos manufacturados en logias y gremios, respectivamente. Dichas logias y gremios de los siglos XII y XIII establecen tanto jerarquias como reglamentos para su funcionamiento $\mathrm{y}$ producción. "La diferencia fundamental entre las logias y los gremios consiste en que son una organización laboral jerárquica de asalariados, mientras los segundos, al menos originariamente, son una asociación igualitaria de empresarios independientes». (18).

Las logias conformaban grupos de artesanos y constructores comprometidos en levantar las grandes catedrales bajo la responsabilidad de dos directores, uno administrativo y otro artístico; al mando de éste se encontraban los maestros y los oficiales. "La función del maestro de obra (magister operis), al que incumbia la provisión de materiales y de la mano de obra, y del arquitecto (magister lapidum), que era responsable de la 
colaboración artística, de la distribución de tareas y de la distribución de las distintas actividades... Una parte de los operarios constituía el personal estable de la logia, que continuaba ligada al arquitecto después de la terminación de un trabajo, $y$ otra parte cambiaba cada vez yse reclutaba en el curso del mismom. (19).

En este sentido, los gremios cohesionaban los trabajadores que laboran en los mismos oficios, establecian los derechos y relaciones con los patrones, intermediaban las desavenencias entre los artesanos, controlaban los precios y la calidad de los objetos fabricados, auxiliaban a los productores y sus familias en los momentos criticos, y controlaban la oferta e idoneidad profesional.

Cada gremio se componia de distintos talleres, en cada uno predominaba un maestro sobre oficiales y aprendices. El sistema de aprendizaje se iniciaba «a la edad de trece o catorce años. En algunos casos, la familia debia pagar al maestro por sus enseñanzas, aunque en otros casos los aprendices percibian una paga... Tras un periodo de cinco o seis años, el aprendiz recibía habitualmente un certificado, y al pasar un test oficial, que a menudo incluía la elaboración de una pieza maestra, estaba en condiciones de obtener el rango de maestro, quien podía abrir su propio taller y tomar aprendices. El proceso para llegar a ser maestro era largo y arduo, y pocos alcanzaban este estatus». (20).

Cambios decisivos suscitaron el establecimiento del Renacimiento en Italia impactando los ámbitos sociales, políticos y culturales. En estos últimos se destaca la diferenciación entre el arte y la artesania, el reconocimiento de los creadores como artistas y sujetos particulares, la consecuente generación de la idea de genialidad, la conquista de la representación de la realidad y la conceptualización moderna del arte.

Al respecto dice Bayer: «los objetivos del arte se hacen autónomos, el arte se independiza y se convierte en laico, como puede verse en Masaccio. De aqui nace la pintura que representa figuras por ella misma. Se requiere la enseñanza de los maestros pintores, no ya de los teólogos... El gusto por el mundo sensible es decisivo. El universo material, de ahora en adelante, inspira amor por sí mismo y ya no como lenguaje simbólico. A esto se debe la primera conquista de Florencia: el cuerpo y la figura humana... El artista requiere la intervención, en su propio naturalismo, de la imaginación y la memoria, es decir, una constante colaboración del pensamiento... La estética del Renacimiento Italiano del siglo XVI se distingue por el descubrimiento del individuo: l'uomo singolare. Ya no encontramos en esta época el elemento gregario de un grupo de fieles o una religión, sino la composición única de elementos físicos, psiquicos e intelectuales. Entre estos individuos, el Renacimiento ha podido distinguir y ha visto surgir varios hombres que no eran sólo manifestaciones interesantes del genus homo, sino que encarnaban dentro de si a muchos seres humanos: es el uomo universale, el genio universal, por ejemplo Dante, Alberti y más que nadie Leonardon. (21).

Los dos últimos artistas cuestionaron el monopolio de la formación artística bajo la exclusividad de los gremios, aunque reconocian en sus enseñanzas el desarrollo de la pericia técnica, también criticaban la incapacidad para la formación integral, dentro de los presupuestos humanistas, es decir inherente a «la recuperación de la herencia cultural clásicas. Además la creación conjunta ni el rol social de los gremios se encontraban acorde con la nueva expresión de la visión particular y las libertades de movilización de una ciudad a otra, de escogencia de los patrones y de encargos; conquistas alcanzadas por los artistas del Renacimiento.

Estas posturas dieron como resultado la creación de las "Academias", lugares donde los maestros y los estudiantes intercambiaban experiencias, conceptos y teorías sobre las prácticas artisticas». Tales academias renacentistas consistian más bien en grupos de 
artistas de edades diversas, algunos neófitos y otros artistas consumados, que se reunian para dibujar o para contemplar las demostraciones que hacian otros, de técnicas o principios novedosos, o bien para discutir teorias del arte y otras tendencias culturales de carácter general". Lo que se puede considerar como una especie de currículo se basaba en "la fundamentación matemática de las artes, la anatomía o la investigación humanistica de la antigüedad». (22). Con ello surgió la relevancia del sustrato teórico que subyace en toda obra de arte, no en vano Leonardo decia: «la pintura es una cosa mental».

La técnica de dibujo se adquiría mediante etapas sucesivas de la copia de dibujos o grabados de maestros, de modelos de yeso o reproducciones de esculturas clásicas y del estudio de la figura humana natural; solo hasta después de alcanzar el dominio de lo bidimensional y lo tridimensional en la representación gráfica, el estudiante no empezaba a pintar.

La primera institución de formación artistica fue la Academia del Disegno, creada por Giorgio de Vasari en 1562. En 1593 inició clases en Roma la Academia di S, Luca, organizada por Frederico Zuccari; mientras en Bolonia los hermanos Carracci abrieron la suya. Las academias privadas proliferaron entre finales del siglo XVI y comienzos del XVII y sus directores y maestros consideraban que «la pintura era una ciencia que podía enseñarse a partir de una serie de reglas fijas, y tales reglas podian descubrirse a través del estudio de los buenos maestros». (23).

La Academia Francesa de Pintura y Escultura se fundó a mediados del siglo XVII; en Febrero de 1648 se iniciaron labores y se dictaminaron las reglas de organización y académicas. Los profesores seleccionados impartian sus enseñanzas durante un mes de forma rotativa, con el fin de evitar la influencia excesiva sobre los estudiantes; durante este periodo se dedicaba a seleccionar el modelo, orientar las clases $\mathrm{d}$ dibujo del natural a través de conferencias o lecciones, y efectuar correcciones a los trabajos de los estudiantes. La Academia tenía tapotestad de dictar «cánones estéticos» que «valiañ como si fueran leyes y se esperaba que fuera (sic) cumplidas por todos los miembros sus'? actividades de educación artística».

El programa establecía que la Academiadebia impartir la formación teórica, cuyos contenidos estaban bajo la supervisión de la monarquía para preservar el «estilo oficial y la ideologia det reinom; mientras que el componente téçnieo estaba a cargo de los académicos en sus talleres. En estos talleres se implantaron tres niveles de formación: inferior dedicado a copiar dibujos de los profesores, intermedio dondefos. estudiantes dibujaban a partir de modelos de - yeso, y superior donde representaban de manera directa el modelo(24). Este programa en esencia viabiliza la politica cultural de la Corona intercsada en mantener su prestigio con caráctet propagandista; al tiempo que el componente práctico proviene de las orientaciones dadas. $\overrightarrow{p o r}$ Leonardo en su Tratado de la Pintura, el cual dé hecho prevalece en gran parte hasta nuestros diass.

El Siglo de las Luces o de la Ilustración es ê término utilizado para describir las tendencias de la cultura y del pensamiento en Europa América durante el siglo XVIII, previas a lar Revoluciones Norteamericana y Francesa. A este término recurrieron con frecuencia los escritores de este periodo para señalar diferencia con los siglos de oscuridad e ignorancià superada y la apertura a una nueva edad iluminada por la luz de la razón, la ciencia y e respeto a la humanidad. Además las ideas de varios pensadores sirvieron como guia para el liberalismo político y económico. La ilustración en el mundo consolidó un paso clave en la relativización del poder eclesiástico y el crecimiento del secularismo actual. 
Durante el siglo XVIII la Academia Francesa sirvió de modelo al resto del mundo. Entre 1720 y 1791 funcionaron veinticinco academias en las ciudades más importantes del mundo. Entre ellas la de San Fernando (Madrid,1752), la de San Carlos (México,1783) y la de Filadelfia (1791). La diferencia estaba en que la mayoria de instituciones artísticas no se crearon con fines politicos, sino que obedecían más a las demandas de la incipiente industrialización y el comercio. (25).

Al finalizar el siglo XVIII los talleres de Francia con fama «del patrón y de sus lecciones», es decir, por la calidad de su instrucción, comenzaron a tener gran solicitud de ingreso; pero también porque paulatinamente se fueron liberando de la normatividad académica. Dentro de ellos fueron altamente valorados los de David y Gros que promovian el estilo neoclásico; el de Gleyre donde se formaron los pintores impresionistas; el de Cormon que dio luces a los postimpresionistas; y el Moreau donde estydiaron los artistas fauvistas.

La formación en los talleres se dividia en dos sesiones, la primera en la mañana los participantes se dedicaban a pintar y dibujar; por la tarde visitaban los museos para realizar copias de obras maestras. En la labor académica participa un monitor encargado de orientar los ejercicios y el trabajo del maestro consistía en explicar, criticar y proponer correcciones un día

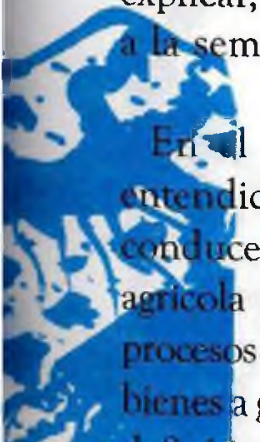

siglo XIX la Revolución Industrial dida como el proceso de evolución que ce a una sociedad desde una economía tradicional hasta otra caracterizada por ss de producción mecanizados para fabricar a gran escala obligó a establecer de manera iva la formación en diseño dedicado a la cración de nuevos productos y servicios. A partir de la Revolución Industrial la producción empezó a rezflizarse en grandes empresas o fábricas en lugar de pequeños talleres domésticos y artesanales, con lo cual se aumentó la especialización laboral.

Su desarrollo dependia de una utilización intensiva del capital y de las fábricas y maquinarias destinadas a aumentar la eficiencia productiva. Históricamente se ubica su origen en Inglaterra de donde se expandió. Paises como Francia, Bélgica, Alemania y Estados Unidos experimentaron procesos parecidos a mediados del siglo XIX; en Suecia y Japón se produjo a finales del siglo; en Rusia y en Canadá a principios del siglo $\mathrm{XX}$; en algunos paises de Latinoamérica, Oriente Próximo, Asia central y meridional y parte de África a mediados del siglo XX.

Las demandas del sector productivo, arriba enunciadas, no fueron resueltas por las academias de Bellas Artes, por lo cual hubo la necesidad de experimentarse con programas especificos para formar diseñadores industriales. Es el trabajo de las Escuelas Francesas de Artes Decorativa, de las Escuelas de Comercio y Politécnicos en los Estados Germánicos y de las Escuelas de Diseño en Inglaterra, hasta la creación de la Bauhaus fundada en Weimar en 1919 por el arquitecto Walter Gropius, quien se propuso aunar la Academia de Bellas Artes y la Escuela de Artes y Oficios, como se explicará más adelante.

En este mismo siglo van a surgir variaciones al modelo francés predominante. Es el caso de las Academias Alemanas donde se iniciaron una serie de críticas encaminadas a abandonar la rigidez de las reglas y dejar al estudiante "demostrar su talento particular y las cualidades especiales de su manera de mirar los objetos"; simultáneamente se clama por una relación más personal entre el maestro y sus estudiantes. Aqui se detecta la influencia de la educación romántica que exige la libertad de expresión. La solución fue iniciada por la Academia de Dusseldorf cuando se establecieron las «clases 
magistrales", ello consistia en que al lograr los estudios básicos el estudiante podia solicitar un maestro permanente para culminar los estudios superiores. (26).

La educación artistica se incorpora a la formación universitaria en las universidades norteamericanas de Harvard, Yale y Princenton. Yale en 1863 inicia labores académicas con el firme propósito de profesionalizar "pintores, escultores o arquitectos», complementado con cursos de historia y crítica del arte, y difundir exposiciones de muestras temporales y de colecciones.

En1873 Harvard inaugura una serie de cursos sobre historia del arte clásico y renacentista para enseñar «las bellas artes como expresión de las condiciones morales e intelectuales del pasado"; luego se introdujeron talleres de dibujo y pintura, con poca concurrencia porque la intención de la institución no era formar artistas profesionales... Pricenton tenia un recorrido considerable comprendido entre 1831 y 1882 con cursos sobre antigüedades romanas, arqueologia, historia y filosofia del arte. En síntesis estas universidades plantean tres modelos de educación artística: la primera tiende a la integralidad entre la práctica, la teoría y la difusión del arte; la segunda se centra en la teoría del arte complementada con talleres; y la tercera se dedica solo a la teoria del arte. Hacia 1901 existian cuarenta y siete instituciones que ofrecian formación y artística; pero solamente Yale y Stanford otorgaban títulos profesionales

El siglo $X X$ ve surgir cuatro fuertes corrientes en los programas de educación y de formación artistica: la llamada escuela de la autoexpresión creativa; la de integración curricular; la expansión de la Bauhaus; y la racionalista científica, cuya mejor concreción es la educación artistica basada en disciplinas, conocida por la sigla DBAE.
La corriente auto expresionista toma las convicciones del idealismo romántico del siglo XIX que consideraba al artista como el guia del conjunto social. Fue el movimiento que inició la pedagogía infantil, que cuestionó y se opuso a las disposiciones de la academia, y que adelantó la ruptura producida por las vanguardias guiadas por el concepto de la libre capacidad de creación artística. Esta corriente se refleja en una postura pedagógica que propende por la disminución del control social y el desarrollo de la creatividad y la expresión personal. La educación que tenía como centro el niño era el lugar privilegiado para implementar laautoexpresión creativa. De manera habitual es definida «como un método A para evitar la imposición de las ideas de los adultos* en el cual se percibia al niño como un artista orientada por freudismo, la libertad, la

y creador nato; los aportes del metáfora de la liberación de las inhibiciones y la represión

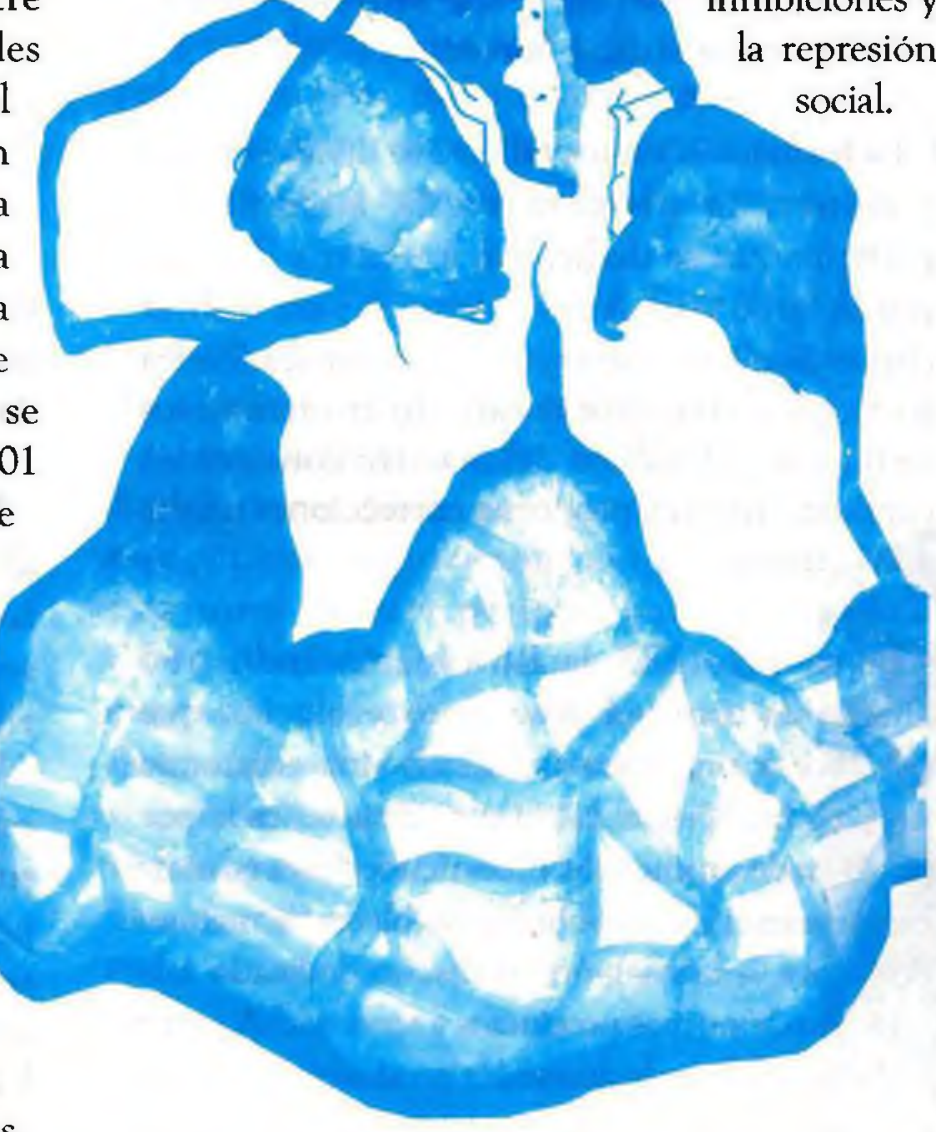


Las experiencias mejor conocidas tienen dos etapas: la primera, que va desde finales del la Primera Guerra Mundial hasta los años treinta, fue desarrollada por algunos artistas-profesores. Las estrategias empleadas para su aplicación consistian en estimular la capacidad imaginativa «con palabras o a través de experiencias visuales o táctiles, o bien ayudándoles a recordar experiencias vividas». Sus principales exponentes fueron Franz Cizek en Austria; Marion Richrdson en Inglaterra; Florence Cane, Natalie Cole y Victo D 'Amico en los Estados Unidos.

La segunda etapa, vigente entre 1945 y 1960 , tiene como representantes destacados a Viktor Lowenfeld y Herbert Read. Consideraban al niño como un artista «encargado de expresar... Verdades universales, a través de los símbolos unificadores del inconsciente colectivo, una expresión que habia de promover el avance de la paz y la civilización. El niño artista recibió el papel de salvador de la sociedad». Aunque el mismo Lowenfeld se rectificó diciendo que el niño sólo realizaba «actividades artisticas", esta corriente ha ido perdiendo seguidores, pero conserva trazos en los programas de extensión, de educación noformal y en los talleres privados.

Recibe la denominación de corriente reconstruccionista la convicción que «la educación es una fuerza capaz de transformar la sociedad" y llevada a la práctica con la escuela considerada como «la pieza que equilibra la maquinaria social». Bajo estos preceptos y experiencias en los años correspondientes a la Depresión Económica se adelantó una experiencia significativa realizada en la ciudad de Owatonna (Minnesota, Estados Unidos). A finales de los años sesenta y durante los setenta esta corriente resurgió en el movimiento para "la educación a través de las artes", conocida en Latinoamérica como «educación por el arte», que veia el arte como una estrategia para dinamizar las actividades de la escuela y llevar a cabo acciones con la comunidad.
Por su carácter social buscaba: 1) un arte más aplicado a las experiencias de la vida diaria, 2) integrar las asignaturas del currículo a través de unidades didáctica que tuvieran más de una asignatura en torno a la selección de temas, y 3 ) que facilitara la interrelación a partir de la identificación de problemas vistos por la institución o la comunidad contextual. De esta manera "el arte debia convertirse en un medio de expresión útil, debia enseñarse en relación con los aspectos fundamentales de la vida. Por ejemplo, la propia persona y los propios problemas... A continuación viene la casa...la escuela y luego la comunidad». (27).

Dentro de esta propuesta los niños aprendian los procesos y técnicas básicas de dibujo, pintura y diseño. Luego servian como medio de ilustración de las demás asignaturas; realizaban aplicaciones a la arquitectura como prototipos de diseño de casas, paisajes, interiores o elaboraban proyectos para el diseño de vitrinas o de etiquetas de los productos de las localidades, siempre buscando la integralidad y la aplicación.

La Bauhaus es la escuela alemana de arquitectura y diseño que ejerció enorme influencia en la arquitectura contemporánea, las artes gráficas e industriales y el diseño de escenografias y vestuarios teatrales. Fue fundada en Weimar en 1919 por el arquitecto Walter Gropius, pretendia combinar la Academia de Bellas Artes y la Escuela de Artes y Oficios. La Bauhaus se encuentra basada en los principios del escritor y artesano inglés del siglo XIX William Morris y en el movimiento Arts \& Crafts, sostenia que el arte debia responder a las necesidades de la sociedad y que no debía hacerse distinción entre las bellas artes y la artesanía utilitaria. También defendia principios más vanguardistas como que la arquitectura y el arté debian responder a las necesidades e influencias del mundo industrial moderno y que un buen diseño debia ser agradable en lo estético y satisfactorio en lo técnico. Por lo tanto, 
además de las clases de escultura, pintura y arquitectura, se impartían clases de artesanía, tipografia y diseño industrial y comercial.

En 1930 la dirección fue asumida por el arquitecto Ludwig Mies van der Rohe, que trasladó la Bauhaus a Berlin en 1932. Otros arquitectos y artistas sobresalientes que componían el cuerpo de profesores de la Bauhaus fueron el pintor suizo Paul Klee, el pintor ruso Wassily Kandinsky, el pintor y diseñador húngaro László Moholy-Nagy (que fundó el Instituto de Diseño de Chicago siguiendo los mismo principios de la Bauhaus), el pintor estadounidense Lyonel Feininger y el pintor alemán Oskar Schlemmer.

Cuando los nazis en 1933 cerraron la escuela, sus ideas y sus obras eran ya conocidas en todo el mundo. Muchos de sus miembros emigraron a Estados Unidos, donde las enseñanzas de la Bauhaus llegaron a dominar el arte y la arquitectura durante décadas, contribuyendo enormemente al desarrollo del estilo arquitectónico conocido como International Style. El estilo de la Bauhaus se caracterizó por la ausencia de ornamentación en los diseños, incluso en las fachadas, asi como por la armonía entre la función y los medios artisticos y técnicos de elaboración.

Con el nombre de racionalismo científico se alude a las ideologias que se amparan en ella, como el darwinismo social de finales del siglo XIX y principios del XX. Después de la Segunda Guerra Mundial en el contexto de las carreras armamentista y espacial dicha corriente optó por las disciplinas definidas en términos científicos como base para la reforma del currículo y para hacer más competitivo el mundo occidental; tal situación alimentó el movimiento en favor del conocimiento de las disciplinas interesadas por el conocimiento en sí mismo, de la manera como indagaria el científico puro; a lo cual se aunó el afán técnico de medir los logros obtenido dando lugar a la evaluación objetiva de los resultados.
En dicha posición se ven reflejados los distintos intereses de los poderes económicos y militares como respuesta directa a las presiones de la Guerra Fria y a los intentos de diseñar unas politicas educativas que pudieran hacer frente a la Unión Soviética. No obstante, su propósito en el aprendizaje por descubrimiento y la idea que los estudiantes deben ser activos en el momento de elaborar conocimientos, aportaban propuestas liberadoras dentro de los objetivos educativos.

De igual manera la evaluación de resultados también se encontraba orientada por la ciencia, como una aplicación de los instrumentos técnicos derivados de los métodos cientificos y preocupados por la observación, la medición y la cuantificación exacta. Este componente fue asimilado por la educación como una técnica para evaluar los aprendizajes de los estudiantes y valorar los conocimientos que habian adquirido a través de la enseñanza.

Jerome Bruner estableció un paralelo entre la ciencia y el arte, por ejemplo en el uso de palabras como hallazgo casual e intuición, habitualmente asociadas con el arte, para describir las actividades del científico. Con esto dio la oportunidad a los educadores artisticos en el sentido que la enseñanza del arte podía ser beneficiada si asumia la ruta trazada por los educadores cientificos. Actualmente la tendencia predominante de la educación artistica consiste en un parece ser una propuesta pedagógica motivada por las iniciativas del currículo centrado en las disciplinas, enfatizando el orden y la estructura que deben acompañar a la producción artistica, la historia del arte, la critica y la estética, cuya mejor expresión es la Educación Artistica Basada en Disciplinas, cuyos principales planteamientos se describen en el siguiente apartado. Entonces, ¿Es posible ampliar los principales contenidos de las distintas teorías contemporáneas que fundamentan y orientan la educación artistica en la actualidad?. 


\section{ANÁlISIS DE LA ACTUAL EDUCACIÓN ARTÍSTICA}

\subsection{Teorias Contemporáneas de la Educación Artística}

En la actualidad existen varias tendencias con una larga trayectoria sobre la enseñanza del arte y la educación artística. La primera conocida como Educación Artistica destaca la práctica del arte enfatizando los valores estéticos, artísticos y culturales con dos enfoques pedagógicos direccionados por la concepción sobre el arte predominante, uno privilegia la libre expresión y los otros procesos comunicativos. (28).

La segunda denominada educación ArtísticoEstética desarrollada en los Estados Unidos con el nombre de Discipline-Based-Art-Education o DBAE, que impulsa la producción artistica, la estética, la critica y la historia del arte. Esta tendencia es avalada por la Getty Center Foundation for Education in the Arts donde laboran investigadores como Howard Garnerd, Elliot Eisner, Brent Wilson, Ralph Smith y Marjorie Wilson. (29).

La Educación Artística como Disciplina (DBAE), se fundamenta en un cambio epistemológico de la misma y en una nueva propuesta curricular. Sus orígenes se remontan a los debates conceptuales y curriculares de los años sesenta. En los que se trató fundamentalmente de valorar la relación entre arte y conocimiento y como consecuencia la real dimensión de la educación artística en el contexto de la educación general. Se debe puntualizar que su alternativa plantea ser ampliamente reflexiva y centra los razonamientos sobre el arte como una forma de conocimiento humano. (30).

El centro de la DBAE es la formación artística inmersa en la educación general organizada en torno a cuatro materias directamente interrelacionadas: la estética, la producción artística, la historia del arte y la critica del arte, que establecen el conocimiento base del arte: conceptos, ideas, principios, teorías, técnicas. El objetivo final consistiria en que el estudiante adquiera una cultura, especialmente la artística. Un contenido estructurado de la materia, de los contenidos artísticos, de los conceptos, generalizaciones, procedimientos y técnicas propios de la disciplina. (31).

Howard Garnerd informó sobre el proyecto denominado Arts PROPEL desarrollado en la Universidad de Harvard donde se demostró la utilidad de implementar la producción, la reflexión y el desarrollo de la percepción artística. (32).

La educadora brasilera Ana Mae Barbosa interpretando las propuestas del DBAE ha propuesto la Metodología Triangular organizada alrededor del quehacer artístico, la lectura de la imagen y la historia del arte. (33).

En la tercera llamada Educación Estética el arte se asume como parte de la vida cotidiana en relación con el contexto y es desarrollada con el trabajo transdisciplinario. En esta tendencia la estética de la obra de arte se integra con lo estético de lo cotidiano. (34).

Lo anterior demuestra que vivimos en un mundo en cambio permanente. Una de las características esenciales de nuestra época es el de los grandes, profundos e intensos cambios producidos fundamentalmente en el ámbito del pensamiento y la cultura y estos han producido y producen como efectos más inmediatos, cambios en ideologías politicas, transformaciones sociales, en fin, rápidas evoluciones en la educación y la cultura.

De aquí se comprende que durante este siglo, el debate en el campo de la educación artística se haya planteado en términos de polarización 
entre aquellos que ven el arte como expresión personal y otros que se centran en la enseñanza de los contenidos. Es importante comprender las diferencias que las separan. Las artes poseen la virtud de la implicación afectiva y el aprendizaje participativo, significan el triunfo de la vida, de los sentidos, de la sensibilidad, de los sentimientos, de las vivencias, de la fantasia, la memoria y la imaginación.

La virtud de la ciencia, en cambio, consiste en el análisis, la comprensión y la explicación de objetivos y la precisión, supone el triunfo del pensamiento racional, mientras que las humanidades poseen la virtud del interés por la acción ética y el desarrollo de las personas. Cada uno de estos campos de estudios requiere sus propias formas de conocimiento y es esencial para completar la imagen de la realidad total. Cuando predomina una determinada corriente es fácil convertirse en dogmáticos y que se pierda el equilibrio y la complementariedad entre las humanidades y las ciencias. Por lo cual la educación artística tiene un papel fundamental que desempeñar como parte de la educación general, cuando se busca el clásico equilibrio que subyace en la formación integral.

La educación artistica de nuestra época, la que enfatizamos, debe ir dirigida a que las personas sean capaces de comprender, asumir y transformar con mayores posibilidades y garantías estas evoluciones. Nuestra propuesta rechaza una educación artística basada en posiciones parciales, basada sólo en enfoques expresivos, productivos o instrumentales; en otras palabras, basada en el "solo hacer", que es lo tradicionalmente ha predominado.

La educación artística por la que propendemos parte de una idea de arte amplia y general e integradora entre los dominios científicos y artísticos que confluyen en la educación artística, inscrita además en los contenidos de lo glocal, es decir dinamizar, pensar y actuar en lo local pero teniendo en cuenta los referentes universales. Fundamentada en una valoración sobre los procesos que dan lugar al hecho artistico; en el cual los aspectos expresivos y de producción, sin suspenderlos, no deben superar a los que permiten desarrollar las competencias reflexivas y perceptivas; entendiendo por ello potenciar tanto la sensibilidad (el sentir) como la sensorialidad (los sentidos), aunada a la apropiación y dinamización de la cultura. En este sentido Bruner afirma que ael lenguaje de la educación es el lenguaje de la creación de la cultura, no del consumo del conocimiento o la adquisición de conocimientos solamentem. (35).

En definitiva, necesitamos una educación artistica que entienda el arte como parte del conocimiento humano, esto significa que posea una estructura propia inscrita en una más amplia del conocimiento general al que no se opone sino que lo complementa y lo enriquece de gran manera. Comprometidos con el firme propósito de hacer de la educación artística un saber cada vez más significativo por contribuir al desarrollo integral de nuestros conciudadanos, al tiempo que construye elementos identitarios basados en la permanente creación cultural. 


\section{NOTAS}

(1) ARAÑO GISBERT, Juan Carlos. Arte, Creación y Creatividad. http://www.quadernsdigitals.net/ articuloquaderns.asp? IdArticle $=551$

(2) LOWENFELD, Victor y BRITAIN, W. Lambert. Desarrollo de la Capacidad CreadoraBogotá. Ed. Kapelusk, 1984.

(3) TERIGI, Flavia. Reflexiones Sobre el Lugar de las Artes en el Currículo Escolar en AKOSCHKY, Judith, et al. Artes y Escuela. Barcelona, Ed. Paidós, 1998, pág. 13-91.

(4) MONTAÑA, Antonio. ¿Que es Arte?. Bogotá, Ed. Instituto Colombiano de Cultura, 1972, pág. 16-18.

(5) FERNÁNDEZ ARENAS, José. Arte Efimero y Espacio Estético. Barcelona, Ed Antropos, 1988.

(6) SÁNCHEZ VÁZQUEZ, Adolfo. Invitación a la Estética. México, Ed. Grijalbo, 1992, pág. 145-249.

(7) POLI, Francesco. Producción Artística y Mercado. Barcelona, Ed. Gustavo Gili, 1976.

(8) Ibídem.

(9) GADAMER, Hans-George. Verdad y Método. Valladolid,Ed Sígueme, 1967.

(10) ACHA, Juan. Introducción a la Creatividad Artística. México, Ed. Trillas,1992.

(11) HORTA MESA, Aurelio A. «El Componente Pedagógico en la Formación
Artística y Cultural» en Memorias del Primer Seminario de Formación Artística y Cultural. Ministerio de Cultura. Santafé de Bogotá, ED. Imprenta Nacional de Colombia, 2000, p.86-87.

(12) READ, Herbert, Educación por el arte. Buenos Aires, ED. Paidós, 1999.

(13) ARAÑO GISBERT, Juan Carlos. Op. Cit.

(14) Ibidem.

(15) EFLAND, Arthur D. Una Historia de la Educación del Arte. Barcelona, Ed. Paidós. 2002, p. 26.

(16) Ibídem, p. 31-32.

(17) Ibídem, p. 39-41.

(18) HAUSER, Arnold. Historia Social de la Literatura y del Arte. Barcelona, Ed, Guadarrama/Punto Omega, 1980, p.311.

(19) Ibídem, p. 305.

(20) EFLAND, Arthur D. Op. Cit., p. 47.

(21) BAYER, Raymond. Historia de la Estética. La Habana, Ed. Instituto Cubano del Libro, 1971, p. 101-102.

(22) EFLAND, Arthur D. Op. Cit., p. 5556.

(23) Ibidem, p 56-61.

(24) Ibidem, p. 64-66.

(25) Ibídem, p. 66-80.

(26) Ibídem, p. 81-98. 
Aproximación a la epistemologia de la educación artistica.

(27) Ibídem, p.305-306.

(28) OLAYA, Olga Lucía. «QQué sẹ Espera del Docente de las Artes Plásticas y/o Visuales en el Aula? «En Memorias Primer Seminario de Formación Artística y Cultural. Ministerio de Cultura. Santafé de Bogotá, ED. Imprenta Nacional de Colombia, 2000, 214 p.

(29) Ibídem.

(30) EISNER, Elliot. htpp:// www.getty.edu/artsednet/.

(31) Ibídem.

(32) GARNERD, Howard. Educación artística y desarrollo humano. Buenos Aires, ED. Paidós, 1994.

(33) BARBOSA, Ana Mae. A imagen no Ensino de Arte. Sao Paulo, ED. Perspectiva, 1986.

(34) READ, Herbert. Op Cit.

(35) BRUNER, Jerome. Realidad Mental y Mundos Posibles, Barcelona, Ed. Gedisa, 1994. 